Ethiopian Journal of Environmental Studies \& Management 7 Suppl.: 744 - 753, 2014.

ISSN:1998-0507

doi: http://dx.doi.org/10.4314/ejesm.v7i1.5S

Submitted: July 23, 2014

Accepted: November 05, 2014

\title{
ESTABLISHING THE RELIABILITY AND VALIDITY OF ENVIRONMENTAL ATTITUDE SCALE AMONG NIGERIAN SAMPLE
}

\author{
ILEVBARE , F.M. \\ Department of Psychology, Obafemi Awolowo University, Ile-Ife, Nigeria \\ E-mail: femilevbare@oauife.edu.ng
}

\begin{abstract}
Most of the western established instruments for measuring environmental attitudes lack appropriate validation among Nigerian population because cultural variation may influence the individual's experience. A 20-item Likert type scale was developed and used to measure attitudes toward environmental issues among 1200 participants in South-western, Nigeria between 15 to 76 years with a mean age of 24.49 years $(S D=8.51)$. Results of a Principal Component Analysis using Varimax factor rotation produced three factors with Eigen values of more than 1 which accounted for $44.896 \%$ of the total variance. The reliability analysis yielded a Cronbach Alpha of 0.64 and Spearman-Brown split-half reliability of 0.71 obtained for the scale was considered conceptually meaningful. This result suggests that the Environmental Attitude measure is valid and could be used to assess the extent to which individual respond consistently favourable or unfavourable manner with respect to the environment. With these justifications, the EAS is potentially more suitable for Nigerian populations. Nonetheless, given limitations, findings should be considered preliminary.
\end{abstract}

Key Words: Environmental attitude, Scale, Reliability, Validity, Nigerian sample

\section{Introduction}

In view of the fact that man affects the environment, the responsibility of taking purposeful collective action that may harmonize human existence with the rest of the environment falls on man. It is disheartening that man is yet to possess adequate capability and take responsibility for their actions which would enable him to ensure a total harmonious relationship with the environment (Olokesusi, 1987). Government and policy-makers have made various attempts directed at creating environmentally friendly mindset and positive environmental attitude among residents which rely on command and control approach that is, environmental legislations and environmental management initiative, yet this has not achieved the desirable impact. In the latest Environmental Performance Index Report in 2012, Nigeria was ranked among the least performing countries out of 132 (Allwell, 2012). Individuals must consume and generate waste with serious environmental consequences. Furthermore, it has been observed that solid waste management has not succeeded in some cases in Nigeria because of the attitude of the residents/citizens (Ilevbare, 2011). According to Ilevbare (2014), waste generation is conditioned to an important degree by people's attitudes towards waste especially their patterns of material use and waste handling, their interest in waste reduction and minimization, the degree to which they separate wastes and the extent to which they 
Establishing the Reliability and Validity of Environmental Attitude Scale................ILEVBARE, F.M.

refrain from indiscriminate dumping of wastes. A careless attitude permeates the thinking of residents especially, those living in cities and towns. Self-help methods of domestic waste disposal are available and could be explored by individuals and institutions. It has been and is still a common practice to dispose of waste by the most expedient methods available. Such methods might be by open burning or the use of an open dump. However, most residents would take to the easy way of depositing waste along the highway, corners of streets and inside gutters for government agencies to pick up without considering the environmental consequences of such practices.

Environmental attitudes refer to people's favourable or unfavourable feelings towards some features of the physical environment or towards an issue which pertains to the physical environment (Holahan, 1982). Researchers such as Schultz (2000) believe that people's attitudes towards the environment and the type of concern they develop towards the environment, are associated with the degree to which they view themselves as interconnected with nature. Stern and Dietz (1994) agree that a person's attitude towards the environment is based on relative importance that person places on him or herself, other people and the natural environment.

According to Adams (2003), a person's attitude towards the environment is based on his or her general set of values and many factors play a significant role in whether proenvironmental perceptions and attitudes would be manifested in pro-environmental behaviour. Factors such as behavioural intentions, willingness to make a sacrifice, place attachment, a strong internal locus of control and strong and accessible attitudes combined are more likely to lead to environmentally responsible behaviour (KurtenKamp and Moore, 2001). Also,
Schultz, et al. (2004) defined environmental attitude as the collection of belief, affect and behavioural intentions a person holds towards environmentally related activities, or issues. According to Newhouse (1990), there is relatively little research about how environmental attitudes are formed and changed. Most research focused on the more tangible question of impact of specific educational programmes despite the fact that most environmental attitudes are formed as a result of life experiences and not necessarily as a result of educational programmes designed to change attitudes. The more exposure of a stimulus is sufficient according to Newhouse (1990), to enhance an observer's attitude towards the object. According to the researcher, several studies found evidence of this, citing studies by Morgan and Graman (1988), which supports this viewpoint. They however caution that the level of exposure should be high and occur over a period of time, high levels of exposure combined with hands-on contact with the object was found to promote attitudinal change. Information is an important factor that may contribute to attitude change. Newhouse (1990) warns that the value of pure information in changing attitudes is difficult to assess as there are too many other factors involved, such as the source of the message, message content, and the characteristics of the recipients.

Consequently, environmental attitude is occasionally, measured independently from its cognitive, affective and intentional components. Hence, ones attitude towards the environment can become a simple component measure. Behavioural change is a complex process involving the interaction between numerous variables including attitude. One way of changing people's behaviour is by changing their attitudes as research has shown a relationship between attitude and behaviour. There are no consensus on a definition of attitude, because attitude are 
often associated with multiple, and even contradictory values (Schultz, 2001).

The question arising from the above is how we can measure the extents to which individual attitudes toward environment are being measured which are culturally relevant. As good as the attempts at developing an environmental attitude measure is, the observation is that there is no indigenous scale that may be culturally relevant within the Nigerian population; therefore the need for the development of a culturally relevant measure of environmental attitude. Few literature like Berberoglu and Tosunoglu, 1995; Leeming, et al. (1998) reported the development of environmental attitude measures with data based from population in the western world environment.(Turkey and USA)

\section{Method}

\section{Study Area}

The study population comprised residents in South-western, Nigeria. The survey research which is cross-sectional in nature involved residents located in Ife, Ibadan and Lagos. Ile-Ife is an ancient Yoruba city in Osun State, Southwestern Nigeria. Ile- Ife is about 218 kilometers northeast of Lagos. Ibadan is located in South-western, Nigeria. It is the capital of Oyo State and is reputed to be the largest indigenous city in Africa, South of the Sahara. Lagos is also located in the South-western part of Nigeria. On the North and East, it is bounded by Ogun State. In the West it shares boundaries with the Republic of Benin. Behind its Southern borders lies the Atlantic Ocean. The study made use of one thousand and two hundred (1200) residents in South-western, Nigeria. The participants were made up of six hundred and eighty-seven $(57.3 \%)$ males and five hundred and thirteen (42.7\%) females. Their age ranged from 15 to 76 years with a mean age of 24.49 years $(\mathrm{SD}=8.51)$ reported for the participants.

\section{Instrument}

Personal Information Data: This is the first section of the questionnaire. It measures information relating to the sociodemographic variables such as gender, age, educational attainment, and area of residence/locality

Environmental Attitude Scale (EAS): The EAS is a 20-item scale measuring environmental attitude. The Environmental Attitude Scale (EAS) was designed by the researcher for the purpose of this study. The response format is Strongly Agree $=5$ to strongly disagree $=1$. The scale was used in determining the environmental attitudes of participants. High score above the mean indicates a positive environmental attitude and low score on this scale indicates a negative environmental attitude while the median score indicates a moderate environmental attitude. No items was reversed in scoring, all relevant items of the scale answered by participants were equally weighed and then summed together to get a composite score. Sample of items include "Are you concerned about the present state of the natural environment in your locality?", "Do you feel that you have much impact on the natural environment in your area?", "Are you concerned about the illegal dumping of waste in your environment?

The development of items for the Environmental Attitude Scale (EAS) was based on literature review and in depth interviews. Based on the review of relevant studies, items were derived from environmental attitude literatures (Ilevbare, 2011, Schultz et al., 2004). The in-depth interviews conducted were meant to identify what residents feel as their positions with regards to maintaining the natural environment around them. Altogether, an item pool consisting of 24-item was generated. The item pool of 24-item written as measures of environmental attitude was therefore presented to expert judges (Social 
and Environmental Psychologists). Items were retained in the instrument if considered relevant, essential and properly worded by experts. The justification for this was derived from the assertion that the use of expert technique is an acceptable method for achieving content validity (Nunnally, 1978). This method yielded 22-item that received above $80 \%$ support (i.e. experts support) from the expert rating. Thereafter, the researcher used a 5-point Likert type response format; the items were put in a questionnaire format and pre-tested in a pilot study to ascertain the psychometric properties of the test items measure.

\section{Sample and Sampling Procedure}

A multi-stage sampling procedure was followed in drawing this sample. In the first phase, three states (i.e. Osun, Oyo and Lagos) out of the six states in the geo-political zone were selected through the purposive random sampling. In the second phase, the simple random sampling technique was used to select one of the Senatorial district out of the three in each state. The Senatorial Districts so selected are Osun East, Oyo South and Lagos Central Senatorial districts. In the third phase, simple random sampling technique was used to select one of the Local Government Area in each of the selected Senatorial districts. These are Ife Central LGA, Ibadan North-West LGA, and Lagos Mainland LGA. In the fourth phase, the purposive non-random sampling was used to select wards with a high concentration of indigenous Yoruba speaking population. This was with the view of ensuring as uniform as possible a socio- cultural affinity of the participants. In the final phase, the nonrandom convenient sampling technique was used to select the actual participants in the study. This was done by visiting each street and house in the selected wards and administering on the first mature person who agrees to participate in the study.

\section{Data Analysis}

Data collected from the field was subjected to statistical analysis using the Statistical Packages for Social Scientist (SPSS)

\section{Results}

Table I shows the table of communalities before and after. The communalities in the column labeled extraction reflect the common variance in the data structure. 55. 7 $\%$ of the variance associated with item 1 is common or shared variance.

The Scale items were subjected to item analysis procedure to improve the construct validity of the test instrument and items with wide distribution of response alternatives and a significant item-total correlation were selected.(Rust and Golombok, 1995). The 22 items were subjected to factor loading to determine and eliminate item with the least inter-item correlation. Therefore, from the original pool of items, 20-item with the least item-correlation of 0.40 were chosen.(Rust \& Golombok, 1995). Table 4 shows the item-tototal correlation analysis which indicates that item 18 and 19 were deleted (i.e. 2 items) from the Scale. Items deleted are "Frequent flooding experienced is as a result of indiscriminate dumping of waste" and 'Most of the traditional leaves for packaging are responsible for waste generation in my area" Furthermore, using principal component analysis (extraction method) followed by Varimax rotation, the outcome emanating from the principal component analysis suggested three factors with Eigenvalue greater than one accounted for $44.896 \%$ of the total variance. The first factor explained $23.405 \%$ of the total variance while subsequent factors explained only small amount of the total variance (Table 3 )

The most significant measure of reliability is coefficient alpha. In exploratory analyses an acceptable level of coefficient alpha of 0.70 was suggested (Nunnally, 
1978). The alpha reliability of the 20-item chosen was 0.64 while the split-half reliability was 0.71 . In this present study a cronbach alpha of 0.70 was reported for the scale. Hence, 20-item was chosen for the final Environmental Attitude Scale (EAS).

\section{Discussion and Conclusion}

The validation of the Environmental Attitude Scale is a step toward establishing an indigenous measure of peoples' attitude towards their environment in Nigeria. The result presented based on statistical analysis, revealed that more than one domain would be necessary in measuring an indigenous environmental attitude scale. The criteria used in ascertaining the interpretability of results and all were met, including on a given factor shared a common conceptual meaning and finally, the rotated factor pattern demonstrated simple structure that items that had high pattern demonstrated simple structure in that items that had high pattern loadings of 0.40 on one factor also had low loadings on the other factor and each factor had high loadings for some items and low loadings for the other factors. While the factor structure of the environmental attitude measure is statistically justified, the researcher believes that the structure is consistent with face validity as well. At least three items loaded on each retained factor; the items that loaded on different factors measured different conceptual meanings. The domain identified here are positive, moderate and negative environmental attitudes. In order to check the possible dimensionality, the factor analysis was used. Principal components analysis using varimax factor rotation produced three factors with Eigen value of more than 1 . The EAS had satisfactory internal homogeneity and moderate construct validity coefficients (alpha of 0.64), findings that support the use of this scale in environmental research aimed at understanding attitudes. The need for cross-cultural investigation of instruments was however emphasized. This suggests that the scale is suitable for use in Nigeria situation. This was in consistent with the NEP scale developed by Dunlap and Van lieve (2008) which reports an alpha of the scale up to 0.58 after the removal of items with low correlation among Turkish population. The items in the EAS might be useful in other western countries, but comparative testing is needed and the issue of culture-specific should be put into further consideration in the framing of responses from respondents. 
Establishing the Reliability and Validity of Environmental Attitude Scale................ILEVBARE, F.M.

Table 1: Communalities

\begin{tabular}{lll}
\hline Item & Initial & Extraction \\
\hline EAS1 & 1.000 & .557 \\
EAS2 & 1.000 & .348 \\
EAS3 & 1.000 & .404 \\
EAS4 & 1.000 & .501 \\
EAS5 & 1.000 & .586 \\
EAS6 & 1.000 & .429 \\
EAS7 & 1.000 & .359 \\
EAS8 & 1.000 & .374 \\
EAS9 & 1.000 & .660 \\
EAS10 & 1.000 & .563 \\
EAS11 & 1.000 & .389 \\
EAS12 & 1.000 & .540 \\
EAS13 & 1.000 & .465 \\
EAS14 & 1.000 & .517 \\
EAS15 & 1.000 & .631 \\
EAS16 & 1.000 & .255 \\
EAS17 & 1.000 & .564 \\
EAS18 & 1.000 & .141 \\
EAS19 & 1.000 & .173 \\
EAS20 & 1.000 & .479 \\
EAS21 & 1.000 & .461 \\
EAS22 & 1.000 & .481 \\
\hline Extaction & .817 & .
\end{tabular}

Extraction Method: Principal Component Analysis. 
Ethiopian Journal of Environmental Studies and Management Vol. 7 Suppl. 2014

Table 2: Total Variance Explained

\begin{tabular}{cccc}
\hline & \multicolumn{3}{c}{ Initial Eigenvalues } \\
\cline { 2 - 4 } Component & Total & \% of Variance & Cumulative \% \\
\hline $\mathbf{1}$ & 5.464 & 24.837 & 24.837 \\
$\mathbf{2}$ & 2.269 & 10.315 & 35.151 \\
$\mathbf{3}$ & 2.144 & 9.744 & 44.896 \\
$\mathbf{4}$ & 1.765 & 8.021 & 52.917 \\
$\mathbf{5}$ & 1.592 & 7.236 & 60.153 \\
$\mathbf{6}$ & 1.294 & 5.883 & 66.036 \\
$\mathbf{7}$ & 1.077 & 4.893 & 70.929 \\
$\mathbf{8}$ & .977 & 4.443 & 75.372 \\
$\mathbf{9}$ & .874 & 3.971 & 79.343 \\
$\mathbf{1 0}$ & .758 & 3.444 & 82.787 \\
$\mathbf{1 1}$ & .726 & 3.301 & 86.088 \\
$\mathbf{1 2}$ & .623 & 2.834 & 88.922 \\
$\mathbf{1 3}$ & .476 & 2.162 & 91.083 \\
$\mathbf{1 4}$ & .413 & 1.877 & 92.961 \\
$\mathbf{1 5}$ & .342 & 1.553 & 94.514 \\
$\mathbf{1 6}$ & .316 & 1.436 & 95.950 \\
$\mathbf{1 7}$ & .235 & 1.068 & 97.017 \\
$\mathbf{1 8}$ & .189 & .857 & 97.874 \\
$\mathbf{1 9}$ & .169 & .768 & 98.643 \\
$\mathbf{2 0}$ & .139 & .633 & 99.276 \\
$\mathbf{2 1}$ & .107 & .486 & 99.762 \\
$\mathbf{2 2}$ & .052 & .238 & 100.00 \\
\hline
\end{tabular}

Extraction Method: Principal Component Analysis.

Table 3: Total Variance Explained

\begin{tabular}{|c|c|c|c|c|c|c|}
\hline \multirow[b]{2}{*}{ Component } & \multicolumn{3}{|c|}{ Initial Eigenvalues } & \multicolumn{3}{|c|}{ Extraction Sums Squared Loadings } \\
\hline & Total & $\%$ of Variance & Cumulative \% & Total & $\%$ of Variance & Cumulative \% \\
\hline 1 & 5.464 & 24.837 & 24.837 & 5.149 & 23.405 & 23.405 \\
\hline 2 & 2.269 & 10.315 & 35.151 & 2.466 & 11.211 & 34.616 \\
\hline 3 & 2.144 & 9.744 & 44.896 & 2.262 & 10.280 & 44.896 \\
\hline 4 & & & & & & \\
\hline 5 & & & & & & \\
\hline 6 & & & & & & \\
\hline 7 & & & & & & \\
\hline 8 & & & & & & \\
\hline 9 & & & & & & \\
\hline 10 & & & & & & \\
\hline 11 & & & & & & \\
\hline 12 & & & & & & \\
\hline 13 & & & & & & \\
\hline 14 & & & & & & \\
\hline 15 & & & & & & \\
\hline 16 & & & & & & \\
\hline 17 & & & & & & \\
\hline 18 & & & & & & \\
\hline 19 & & & & & & \\
\hline 20 & & & & & & \\
\hline 21 & & & & & & \\
\hline 22 & & & & & & \\
\hline
\end{tabular}

Extraction Method: Principal Component Analysis 
Establishing the Reliability and Validity of Environmental Attitude Scale.................ILEVBARE, F.M.

Table 4: Structure Coefficients from Rotated Component Analysis Of EAS (N=1200)

\begin{tabular}{lccc} 
& \multicolumn{3}{c}{ Component } \\
\cline { 2 - 4 } EAS15 & 1 & 2 & 3 \\
EAS12 & .769 & & \\
EAS9 & .723 & & \\
EAS10 & .721 & & \\
EAS4 & .721 & & \\
EAS14 & -.687 & & \\
EAS22 & .653 & & \\
EAS13 & .612 & & \\
EAS20 & .607 & & \\
EAS8 & .606 & & \\
EAS7 & .587 & & \\
EAS11 & .476 & & \\
EAS19* & .476 & & \\
EAS18* & & .754 & \\
EAS5 & & .595 & -.636 \\
EAS6 & & -.551 & .530 \\
EAS2 & & -.423 & .493 \\
EAS16 & & & \\
EAS1 & & & \\
EAS17 & & & \\
EAS3 & & & \\
EAS21 & & & \\
\hline
\end{tabular}

Extraction Method: Principal Component Analysis.

a. 3 components extracted

N.B. $\quad *$ item deleted 
Table 5: Component Matrix ${ }^{\mathrm{a}}$

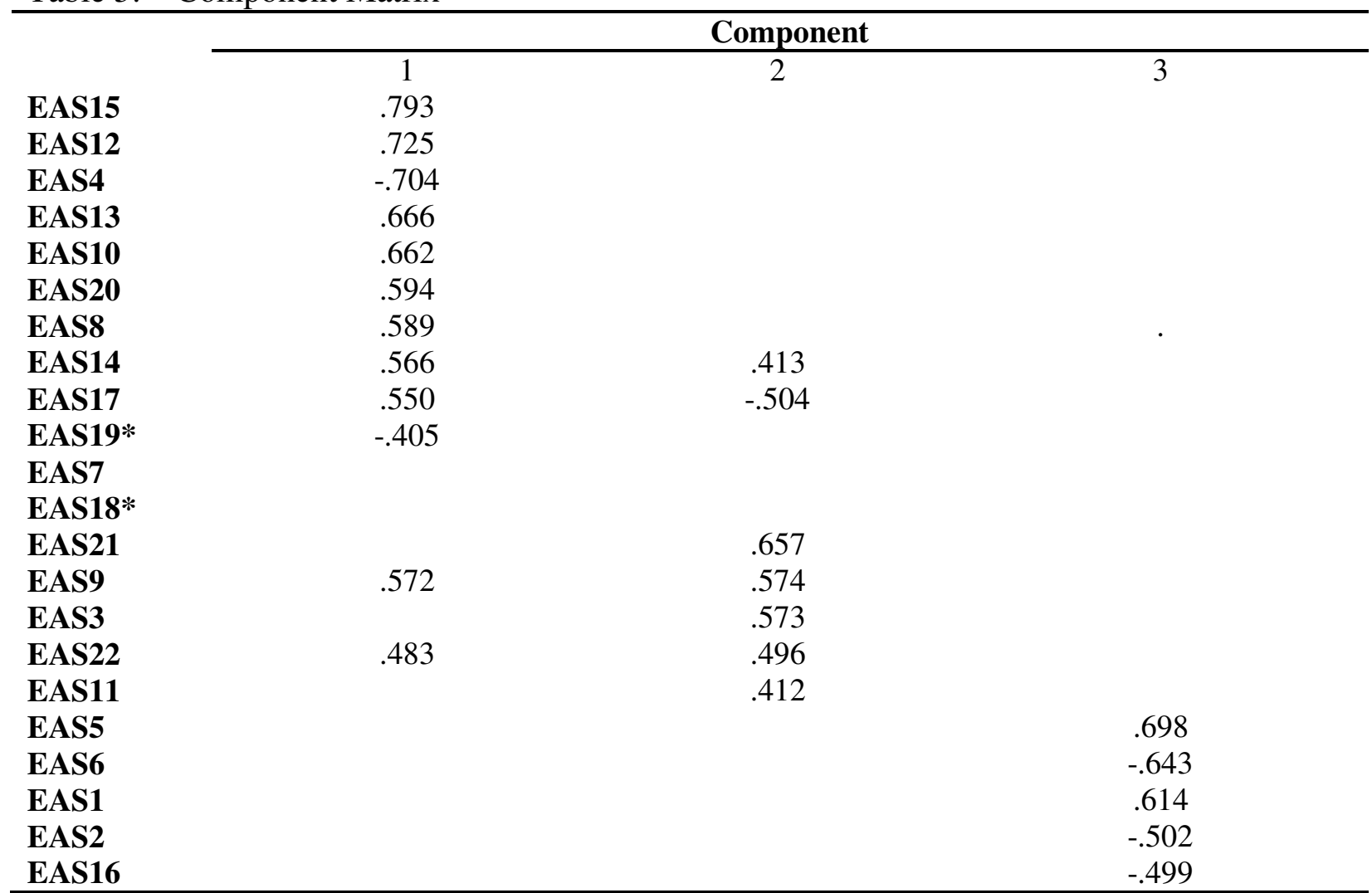

Extraction Method: Principal Component Analysis.

Rotation Method: Varimax with Kaiser Normalization.

N.B. * item deleted

\section{References}

Adams, W.J. (2003). Promoting environmentally responsible behaviour: An evaluation of the global learning and observations to benefit the environment (globe programme). An Unpublished Master's Thesis. University of South Africa

Allwell, O. (2012). Nigeria ranks 119th on Global Environmental Index: Sunday Punch Newspaper, pp. 6

Berberoglu, G. and Tosunoglu, C. (1995). Exploratory and Confirmatory Factor analyses of an Environmental attitude Scale for Turkish University students. Journal of Environmental Education 26(3), 40-44
Dunlap, R.E. and Van lieve, K.D. (1978). The new environmental paradigm. Journal of Environmental Education, 9 (4), 10-19

Holahan, C.J. (1982). Environmental Psychology. New York random house

Ilevbare, F.M. (2011). Attitude towards solid waste management in Lagos State: Predictors and Implications for Environmental Management; Presentation at the 10th, International Conference on Urban Health. BeloHorizonte, Brazil.

Ilevbare, F.M. (2011). Influence of self monitoring and locus of control on attitude towards Solid waste management in Lagos State. 
Unpublished Master Thesis submitted to Obafemi Awolowo University,IleIfe, Nigeria

Ilevbare, F.M. (2014). Locus of Control, Environmental Attitude and SelfEfficacy As Predictors of Environmentally Responsible Behaviour Among Residents in Southwestern Nigeria. Unpublished Ph.D Thesis Submitted to Obafemi Awolowo University, Ile-Ife, Nigeria

Kurten Kamp, K.V. and Moore, C.F. (2001). Egocentrism and anthropocentrism: moral Reasoning about ecological commons dilemmas. Journal of Environmental Psychology, 21, 1-11.

Leeming, F.C., Dryer, W.O. and Brucker, B.A. (1995). Children's Environmental attitude and Knowledge Scale. Construction and Validation. The Journal of Environmental Education, 26(3): 22- 31.

Newhouse, N. (1990). Implication of attitude and Behaviour Research for Environmental Conservation. The Journal of Environmental Education 22(1): 26-32.
Nunnally, J. C. (1978). Psychometric Theory. Second edition: New York: McGraw Hill Book Company

Olokosusi, A. (1987). Characteristics of environmental problems in Nigeria and management Prospects. The Environmentalist, 7(1): 55-60

Rust, J. and Golombock, S. (1995). Modern Psychometrics: The Science of Psychological Assessment In Okurame D. E. (eds). Influence of Psychosocial Factors and Mediatory role of informal mentoring among first-line managers of commercial banks .Unpublished Ph.D thesis, University of Ibadan

Schultz, P.W. (2000). Empathizing with nature; the effects of perspective taking on concern for environmental issues. Journal of Social Issues, 56(3): 391406.

Schultz, P.W. (2001). The structure of the environmental concern; concern for self, other People and the biosphere. Journal of Environmental Psychology, 21: 327-339

Schultz, P.W., Shriver, C., Tabanico, J. and Khazian, A. (2004). Implicit Connections with nature. Journal of Environmental Psychology, 24: 31-42. 